\title{
Winners and Losers in Toll Motorway Renegotiations: An empirical evaluation of the Spanish pioneers
}

\section{Daniel Albalate and Paula Bel-Piñana}

Universitat de Barcelona, Departament de Política Econòmica i Estructura Econòmica Mundial. Av. Diagonal 690, 08034 Barcelona, Spain

E-mail addresses: paulabel@ub.edu (P. Bel-Piñana), albalate@ub.edu (D. Albalate).

\begin{abstract}
This paper evaluates the welfare impact of a toll motorway contract renegotiation in Spain (the AP-7 between Tarragona and Alicante) to illustrate how such a process can affect the long-term welfare of the agents involved. By performing a cost-benefit analysis and examining scenarios that differ from that of the renegotiated agreement, we are able to identify the winners and losers in this process and their respective welfare gains and losses. Our results indicate that the taxpayers experienced the largest gain, being $49.8 \%$ better off, and that the private concessionaire improved its welfare by more than 28\%. However, road users suffered a $7.6 \%$ loss in welfare. According to our simulation an agreement leaving road users indifferent while securing gains for taxpayers and the concessionaire alike would have been possible by negotiating a larger reduction in tolls linked to the extension of the contract duration.
\end{abstract}

KEY WORDS: Concessions, Renegotiations, Motorways, Tolls, Welfare. JEL CODES: H43, L91.

P. Bel-Piñana: Corresponding author. $\mathrm{PhD}$ candidate in Economics at University of Barcelona (Spain).

D. Albalate: Assistant Professor of Economics at University of Barcelona (Spain). He has published research articles in international journals on concessions, public-private partnerships, and infrastructure policy and road safety.

\section{Acknowledgements}

We thank the Spanish Government (ECO2012-38004) and the Government of Catalonia (SGR2009-1066) for their financial support. 


\section{INTRODUCTION}

Financial and budget constraints lead many governments to seek funding for strategic transportation infrastructure projects in the private sector. As a result, there is a growing presence, across the globe, of private interests in joint undertakings with the public sector. Under such agreements, private partners are involved in the design, construction, management and funding of many transportation projects. The increase in public-private partnerships (PPPs) in this area is well documented, but their presence is particularly notable in the toll road sector, above all in Latin America (Guasch, 2004; Guasch et al., 2008; Engel et al., 1996, 2003), Southern Europe (Albalate et al., 2009; Albalate, 2014) and recently in the United States (Engel et al., 2006; Bel and Foote, 2009).

The standard model for contracting out road projects when constructing new infrastructure (greenfield projects) and introducing a payment mechanism based on user payments, with or without budget contributions, is referred to as a Build, Operate and Transfer (BOT) model ${ }^{1}$. Here, the State awards the project by way of competitive auction or bilateral negotiation to a private company and the concessionaire then designs, builds, finances and maintains the infrastructure for a stipulated time period, charging fees to users or taxpayers (shadow tolls). When the concession terminates, operation is transferred to the State. However, recent experience shows that this model generates frequent and early renegotiations for various reasons, including: poor contract design, with agreements being inherently incomplete (Kerf et al., 1998); deficient traffic prediction models, undermined by poor long-term forecasts and uncertain traffic demand (Bain, 2009); fixed contract duration (Engel et al., 1997; Engel et al., 2001); and the strategic behaviour adopted by companies in the bidding process (Athias and Nuñez, 2008).

Spain is one of the most experienced countries with regards to private participation in the toll motorway industry, above all using BOT contracts. The model was introduced in the late $60 \mathrm{~s}$ and subsequently developed to obtain funding for strategic investments. Today, the country's toll motorway network exceeds $3,000 \mathrm{~km}$ in length and more than $60 \%$ of tolled kilometres have undergone at least one contract extension renegotiation. Most of these renegotiations have been the result of contractual incompleteness and the fixed-term nature of the concession, inaccurate forecasting or economic crises that have affected both costs and demand. However, the most recent wave of renegotiations in Spain took place in the late nineties as the government sought to comply with the Maastricht Treaty. This involved the renegotiation of several toll motorway concessions, with contractual extensions being granted in return for lower tolls that could both transfer and reduce logistical costs. These agreements resulted in a significant increase in demand, and meant that many concessions that were due to be terminated in the early 2000s remain in private hands despite public discontent, especially in areas where toll roads concentrate (see Albalate, 2014). Today, Spain operates a mixed funding model where about $80 \%$ of its motorways are publicly funded and 20\% are financed with user fees (Bel and Fageda, 2005; Albalate, 2011).

By focusing on one representative process of renegotiation during this last wave of contract extensions in Spain, this paper makes two main contributions. First, this is as far as we know - the first paper to identify and measure the effect of welfare changes

\footnotetext{
${ }^{1}$ The literature also recognizes other contract types including Build, Own, Operate and Transfer (BOOT), Build, Transfer, and Operate (BTO), Design, Build, Finance, and Operate (DBFO), Rehabilitate, Operate and Transfer (ROT).
} 
provided by a toll motorway renegotiation disaggregated by agents (users, concessionaires and taxpayers). As such, this paper seeks to identify the winners and losers in this renegotiation that saw tolls being reduced and contracts extended. Second, we perform a cost-benefit analysis that can be used as an initial benchmark for implementation when examining the financial welfare effects of any ongoing or finalized toll motorway renegotiation.

The remainder of this paper is organized as follows. In the next section, we briefly review toll road policy and its development in Spain paying special attention to the toll motorway concession analysed here. Section three describes the methodology adopted in computing our cost-benefit analysis. The fourth section presents our main results and the paper concludes with final remarks and conclusions.

\section{TOLL MOTORWAY CONCESSIONS AND RENEGOTIATIONS IN SPAIN}

During the sixties the Spanish economy grew rapidly giving rise to a need for more highways. This was tackled in 1965 via a National Motorways Program. Between 1967 and 1975, private firms constructed more than 2,000 kilometres of toll roads, but the onset of the democratic transition, the economic crisis and a dramatic increase in construction and energy costs paralysed the plan. In the early eighties, following the political transition, a left-wing government opted to build new highways from public funds while retaining tolls on the motorways already constructed, resulting in a mixed motorway funding model (Bel, 1999). This mixed model was further complicated by a series of renegotiations and privatisations due to the financial crisis; in fact, three concessionaires had to be taken into public ownership in 1984. However, policies favouring tolls introduced in 1996 (following a change of government) and plans to boost economic efficiency and fight inflation in seeking to comply with the Maastricht Treaty exacerbated the situation. Between 1996 and 2004, the conservative party awarded 900 kilometres of new toll motorways to private companies and extended the duration of the concession contracts awarded during the dictatorship. The motorway most affected by these renegotiations, and the subject of this study, was the AP-7 (see details below) owing to its length and age. Today, the contracts for the radial motorways providing access to Madrid, which were awarded in the early 2000s, are being reviewed, due to the parlous financial situation, and renegotiations (or even nationalisations) are likely to be the solution offered by the government. The results obtained in this study could be a good indicator of the outcomes for the motorway sector should new renegotiations be undertaken.

\subsection{Case study: The Tarragon-Valencia and Valencia-Alicante sections of the AP- 7 motorway}

The AP-7 is a 980-kilometre long toll motorway (operated under a public-private partnership) that runs along the Mediterranean coast, from the French border to Algeciras. Parallel to it runs the alternative conventional road (the N-340), which is completely public and toll free. The AP-7 was the first motorway concession to be awarded in Spain in the late sixties and today comprises eighteen sections managed by six different private companies. In the intervening years, different sections of the AP-7 have been renegotiated, with the most recent agreements being reached in the late nineties. Here, we analyse the 1997 renegotiations of the Tarragona-Valencia and Valencia-Alicante sections, which have a combined length of 374 kilometres and which record some of the highest average daily traffic volumes in the corridor. 
The latest renegotiations of these sections (31 October 1997) were, according to government sources, aimed at stimulating the use of the motorway in corridors of high economic activity that were absorbing high volumes of traffic. The main changes in the contracts were 34.66 and $32.37 \%$ toll reductions on the Tarragona-Valencia and the Valencia-Alicante sections, respectively, and a 24 million euro ${ }^{2}$ concessionaire investment commitment in new flexible road safety barriers, new road links, access improvements and information system modernization. The toll reductions apply until the end of the concession, while the investment was to be made between 1998 and 2000. By way of compensation, the concession was extended by thirteen years, from 31 December 2006 (the previous termination date) to 31 December 2019.

\section{EMPIRICAL STRATEGY}

This paper seeks to evaluate the welfare impacts of a concession renegotiation involving one of Spain's main toll motorways channelling high volumes of traffic along the strategic Mediterranean corridor. The AP-7 concession was last renegotiated in 1997 and there have been no similar renegotiations in this sector since. We empirically estimate welfare changes disaggregated by agents in order to determine the main losers and winners of this policy. To do so, we empirically conduct a cost-benefit analysis of the actual situation (the renegotiation) and compare these outcomes with the simulated situation (no renegotiation). The three agents included in our cost-benefit analysis are the (1) road users, including those using the motorway and those using the free, parallel, conventional road (N-340) (2) the concessionaire, i.e., the private company operating the two motorway sections, and (3) the government or taxpayers, because the central government in Spain is responsible for both the motorway and the parallel route. Welfare is considered for two scenarios: the renegotiation scenario or the current situation (the last renegotiation between the State and the concessionaire taking place on 31 October 1997 with the concession due to terminate on 31 December 2019) and the no renegotiation scenario (in which the concession was due to terminate on 31 December 2006 with the two sections being transferred to the State in 2007). On the termination of the concession the government must decide if the motorway is to be free, a reasonable assumption if we consider that $80 \%$ of the total kilometres of motorway in Spain are toll free, or if the road users are to pay cost-based tolls, assuming that the government does not wish to obtain a mark-up given its non profit orientation.

\subsection{Methodology}

The cost-benefit analysis (CBA) is conducted over a time horizon of 23 years (19972019), corresponding to the new concession period. First, we conduct the CBA for the renegotiation scenario (R), assuming that road users pay the reduced toll rate from 1997 to 2019 as per the agreement reached. The concessionaire operates and maintains the motorway throughout the period and makes a compulsory investment of 24 million euros (1998-2000).

The government operates the conventional parallel route $(\mathrm{N}-340)$ throughout the period and collects taxes (VAT) from the concessionaire revenues. In the alternative scenario of no renegotiation (NR), the concession terminates in 2006 and between 2007 and 2019 the government has to bear not only the maintenance costs of the N-340 but

\footnotetext{
2 The renegotiation included a further six million euros for the Sevilla-Cadiz (AP-2) section belonging to the same private firm as the Tarragona-Valencia and Valencia-Alicante sections.
} 
also the cost for operating and maintaining the motorway and the 24-million euro investment deemed essential for the good operation of the motorway. In the NR scenario, we first assume that the government does not charge a toll, as is currently the case on most publicly managed motorways in Spain. This means road users only have to pay a toll between 1997 and 2006 when the concessionaire operates the AP-7, but not after this date. We denote this scenario as NR1. Second, we relax this assumption and assume that the government charges cost-based tolls to road users to cover maintenance costs (thus, road users pay tolls throughout the whole period: those actually charged by the concessionaire up to 2006 and cost-based tolls between 2007 and 2019). We denote this scenario as NR2. The CBA for each scenario and each agent is calculated using the following aggregated equation:

$\mathrm{CBA}_{\mathrm{i}}^{\alpha}=\sum_{\mathrm{t}=0}^{\mathrm{t}=\mathrm{n}} \frac{\text { Benefits }_{\mathrm{t}}-\text { Costs }_{\mathrm{t}}}{(1+\mathbf{r})^{\mathrm{t}}}$

where,

$\mathrm{i}=$ each of the agents involved in the scenarios: road users $(\mathrm{U})$, concessionaire $(C)$ and taxpayers $(G)$.

$\alpha=$ each of the scenarios considered: $\alpha=$ R renegotiation; $\alpha=$ NR1 no renegotiation and the government does not charge a toll following the transfer of the infrastructure to the State; $\alpha=\mathrm{NR} 2$ no renegotiation and the government charges a cost-based toll when the infrastructure is transferred to the State.

$\mathrm{t}=$ years.

$\mathrm{r}=$ social discount rate of $5.5 \%$

First, we calculate the net result of renegotiation in terms of the differences between the costs and benefits for each agent in the actual renegotiation scenario. We then compute the net cost-benefit outcome for each agent in the NR scenario (with and without tolls, separately). The costs and benefits included in the analysis are shown in Table 1.

\section{$<<$ Insert Table 1 about here $>>$}

We consider the annual travel time costs on the motorway (AP-7) and on the conventional road $(\mathrm{N}-340)$ as the main welfare determinant for road users, but cannot include intangible welfare factors such as convenience, comfort, safety or utility obtained from the trip, etc. Thus, we consider the total time spent on each of the roadways in computing road user welfare plus the tolls charged to those using the AP-7, which is the standard generalised transportation cost approach implemented in transport economic modelling. As such, average daily traffic is a key variable since all costs and benefits depend to some extent on $i^{3}$ - in this respect, prices have a clear impact on average daily traffic. As our simulated scenarios (NR1 and NR2) imply price changes, we take the $-0.5 \%$ elasticity price, obtained from the estimates for Spain by Matas and Raimond (2003), to compute the resulting traffic after price modifications.

\footnotetext{
${ }^{3}$ Apart from compulsory investment costs that are fixed by law.
} 
Having computed the net results for all agents (see equation 1 above), which means we can present an absolute comparison between renegotiation and no renegotiation, we then measure the relative welfare change produced by renegotiation following equation (2) below.

$\mathbf{W}_{\mathrm{i}}^{\mathrm{g}}=\frac{\frac{\mathrm{CBA}}{\mathrm{CBA}^{\mathrm{R}}-\mathrm{CBA}^{\mathrm{NR}}}}{\mathrm{CBA}^{\mathrm{R}}} * \%$

where,

$\mathrm{i}=$ each of the agents involved in the scenarios: road users $(\mathrm{U})$, concessionaire $(\mathrm{C})$ and taxpayers $(\mathrm{G})$.

$\mathrm{g}=$ no renegotiation government parameter. $\mathrm{g}=1$ if the government does not charge a toll following the transfer of the infrastructure to the State and $g=2$ if the government charges a cost-based toll when the infrastructure is transferred to the State

$\frac{\overline{\mathrm{CBA}^{\mathrm{R}} \frac{-\mathrm{CBA}^{\mathrm{NR}}}{\sqrt{n}}}}{n}$ net result of the renegotiation.

$\mathrm{CBA}^{\mathrm{R}}=$ cost-benefit analysis outcome in the renegotiation scenario

$\mathrm{CBA}^{\mathrm{NR}}=$ cost-benefit analysis outcome result in the no renegotiation scenario, $\mathrm{NR}=\mathrm{NR} 1$ if $\mathrm{g}=1$ and $\mathrm{NR}=\mathrm{NR} 2$ if $\mathrm{g}=2$.

We are interested in presenting these outcomes in relative terms: first, because we wish to identify who the respective winners and losers are in this process of renegotiation; and, second, because we cannot specifically calculate the benefits for road users as their welfare gains are based on the time and monetary savings that make up the two cost variables in the generalized transport cost equation.

\section{RESULTS}

Table 2 shows the disaggregated and specific cost-benefit outcomes and their component factors for road users. The information is reported in both absolute and relative terms for each scenario. According to these estimates, the best scenario for road users is that in which there is no renegotiation of the concession and the government does not charge tolls when the infrastructure is transferred back to the State. Even if the government opts to charge cost-based tolls, road users are still better off than in a scenario of renegotiation and contract extension, as the toll rates under the renegotiation scenario are always higher per vehicle-km than those actually charged by the government. Further, because time costs per user on the motorway are lower than those on the conventional road, more users would take the motorway if prices were lower than in a scenario of renegotiation. This means higher time costs in absolute terms for the motorway users in both no renegotiation scenarios (NR1 and NR2) than in the renegotiation scenario $(2,832.98 \mathrm{M}>2,797.98 \mathrm{M}>2,564.09 \mathrm{M})$, primarily because more drivers will use the toll motorway when it is cheaper (or free), as has occurred since 2007 under public management, but the time costs per driver are much lower due to the faster journey time. As expected, aggregate toll payments decrease in scenarios NR1 and NR2, particularly when the government does not charge a toll after 2006. In short, road users are clear losers in any renegotiations. 


\section{$<<$ Insert Table 2 about here $>>$}

According to our estimates for the concessionaire (Table 3), the best scenario $(+952 \mathrm{M})$ is that of renegotiation. The fact that the concessionaire can exploit the motorway over a longer period seems to offset the lower toll rates and the compulsory investment imposed in the renegotiation. Interestingly, however, the cost-benefit analysis for a scenario without renegotiation would still give the concessionaire a healthy outcome $(+679 \mathrm{M})$ as it could charge a higher toll rate until 2006 and avoid the compulsory investment. Clearly, for the concessionaire, there is no difference in welfare attributable to the government's toll policy on transferring the motorway back in 2006. It is reasonable to assume that the concessionaire, aware of its profit levels without renegotiation, negotiated better conditions in order to reach an agreement. In short, the concessionaire is a clear winner in this renegotiation.

\section{$<<$ Insert Table 3 about here $>>$}

Our estimates for taxpayers (Table 4) show that the best cost-benefit scenario is that in which there is renegotiation, i.e., the prevailing situation. In this scenario the government need not manage the motorway nor invest in it between 2007 and 2019, these costs being borne by the concessionaire and financed by road users. Moreover, the government collects tax revenues (VAT) from the tolls charged for a longer period than in the case of no renegotiation. These factors appear to be the main sources of welfare gain associated with renegotiation. If we observe the cost-benefit outcomes in alternative scenarios, the government's welfare is higher when it charges cost-based tolls as opposed to operating the motorway free of charge. ${ }^{4}$ Clearly this result is driven by the fact that by only charging cost-based tolls taxpayers avoid having to bear any maintenance costs, while VAT can continue to be collected from the publicly owned company managing the motorway. Thus in scenario NR1 (no cost-based tolls), the welfare gain of the renegotiation for taxpayers is lower than the gain in scenario NR2 (cost-based tolls). As such, their net outcome (517 M) is closer to the net outcome under renegotiation $(788.49 \mathrm{M})$ than in the alternative case of free motorway use $(396 \mathrm{M})$. Note that all net outcomes are positive, which means in all scenarios the government's VAT revenues are higher than its expenditure on the maintenance of both roadways (the N-340 throughout the period and the AP-7 in both no renegotiation scenarios). In short, taxpayers are clear winners in the renegotiation.

\section{$<<$ Insert Table 4 about here $>>$}

In absolute terms both the concessionaire and taxpayers obtain similar welfare gains from renegotiation and a scenario of no renegotiation and a toll-free motorway

\footnotetext{
${ }^{4}$ Note that the maintenance costs of the N-340 are higher under no renegotiation. A possible explanation is that until 2006 tolls are higher than in the renegotiation scenario and so many drivers continue to use the free, parallel route (maintenance costs being a function of traffic). These costs are not offset by the savings made after 2007 when the toll falls or is even lifted. Indeed, maintenance costs appear to be lower when the motorway is free (NR1).
} 
(273 M vs. $271 \mathrm{M}$ respectively, see Tables 3 and 4). The taxpayers' absolute gain however is much higher in a scenario of no renegotiation and cost-based tolls on the motorway (392 M, see Table 4), making it the clear winner from this policy.

In relative terms (see Figure 1), the main losers in the renegotiation are road users, with a change in welfare of between $-5.8 \%$ and $-7.6 \%$, depending on the government's toll policy in the no renegotiation scenarios. The worst outcome is obtained by comparing a scenario of renegotiation with that of no renegotiation and the government charging of cost-based tolls after 2007.

\section{$<<$ Insert Figure 1 about here >>}

Relatively speaking, the winners of the renegotiation are those that agreed terms in 1997: the concessionaire and the government (taxpayers). In fact, the agents experiencing the largest relative welfare changes are the taxpayers in each of the scenarios, regardless of the toll policy in alternative scenarios of no renegotiation. Thus, the concessionaire always obtains welfare gains $(+28.64 \%)$ from the renegotiation and is indifferent to the toll policy adopted by the government, and the taxpayers experience a welfare change between +49.8 and $+34.5 \%$ from the renegotiation, the highest figure being associated with the scenario in which the government does not charge tolls after 2006. By contrast, the agents not directly involved in the renegotiation, i.e., the road users, experienced a significant welfare loss across all scenarios.

Yet, the road users' loss could easily have been offset with a larger toll reduction in the 1997 renegotiations (fixed at 34.66 and $32.37 \%$ on the Tarragona-Valencia and the Valencia-Alicante sections, respectively). Adopting the same empirical strategy as above, we can compute the reduction that would have left road users indifferent to the renegotiations.

\section{$<<$ Insert Table 5 about here $>>$}

Table 5 shows the welfare impact assuming different toll reductions so that reductions of 46.3 and $44.1 \%$ (depending on the toll policy of the government in the scenarios of no renegotiation) would have left road users indifferent. Interestingly, these toll reductions would still have provided the concessionaire and the taxpayers with positive welfare changes.

\section{CONCLUSIONS}

Spain is a pioneer in the use of PPPs in the road sector and hence a good framework in which to analyse and evaluate the performance of such partnerships. However, while Spain has experienced many renegotiations of its toll motorway PPPs, no study to date has evaluated their impact on the welfare of the actors involved. Typically these renegotiations involve a change in the tolls charged and the duration of the contract. Indeed, most of Spain's mature motorway concessions have been extended so as to compensate the private concessionaire for a reduction in tolls or for new investments, but the public remain largely unaware of the long-term effects of these decisions on the welfare of road users, the private concessionaire and taxpayers.

This study has shown that the two agents involved in renegotiating the concession - the private concessionaire and the government - for one of the oldest and densest toll motorways in Spain have benefited most, in absolute and relative terms, from the changes to the contract. This means that those who bilaterally renegotiated the 
contract benefited from it at the expense of the road users, who suffer a welfare loss even though tolls are reduced in the short term. The main winner appears to be the government (or the taxpayer), which would account for the fact that many such renegotiations are led by the administration. Indeed, when the government renegotiates the length of a BOT contract in which tolls are paid directly by the users, it can secure notable welfare gains by extending its duration. This gain is attributable to the fact that governments can collect taxes for longer periods under private management and make cost savings by avoiding any maintenance and operation costs.

Reducing tolls but extending the length of the contract, however, resulted in a welfare loss for road users (both those using the motorway and those using the parallel route) in the corridor. Yet, our simulation shows that this could have been avoided by negotiating a greater reduction in tolls, while still guaranteeing welfare gains for taxpayers and for the concessionaire. Indeed, a toll reduction of between 44.1 and $46.3 \%$ would have left road users indifferent. Unfortunately, the general inability of citizens to organise themselves and to be better informed about the impact of such agreements play against their long-term interests. Although myopic road users may consider the reduction in tolls linked to the extension of the contract a benefit in the short run, we show that in the long term they suffer a loss.

It is hardly surprising, therefore, that governments have an interest in extending toll motorway contracts to avoid the public expenditure associated with the management of these roads and the fall in their VAT revenues. This presumably explains why only one concession has ever been transferred back to the State in Spain, while all others have been subject to renegotiation. Likewise, political economy motives cannot be ignored, as incumbents have clear incentives to lower the regulated price of toll motorways taking advantage of the myopic behaviour of current users (voters) who experience a welfare gain in the short run.

Finally, as a result of the renegotiation of concession contacts, taxpayers are better off, which means public finances are healthier. This, in turn, may lead to a general reduction in taxes or to higher expenditure to the benefit of the citizens. All in all, there is probably a transfer of welfare from motorway users to the rest of the taxpayers, something that could not happen with shadow tolls.

Currently, the contracts for the radial motorways providing access to Madrid, which were awarded in the early 2000s, are being reviewed, due to the parlous financial situation created by huge debt burdens, low demand and the competition from free parallel motorways. All the indications are that they will shortly come under renegotiation. In this regard, this paper provides an empirical strategy for evaluating future renegotiations in terms of agents' welfare. 